\title{
Identifying Rational Candidates for Immunotherapy Targeting PD-1/PD-L1 in Cervical Cancer
}

\author{
MISEON KIM ${ }^{1}$, HYOJIN KIM ${ }^{2}$, DONG HOON SUH ${ }^{1}$, KIDONG KIM ${ }^{1}$, \\ HAERYOUNG KIM ${ }^{3}$, YONG BEOM KIM ${ }^{1}$ and JAE HONG NO ${ }^{1}$ \\ ${ }^{1}$ Department of Obstetrics and Gynecology, and ${ }^{2}$ Department of Pathology, \\ Seoul National University Bundang Hospital, Seongnam, Republic of Korea; \\ ${ }^{3}$ Department of Pathology, Seoul National University Hospital, Seoul, Republic of Korea
}

\begin{abstract}
Background/Aim: To investigate the abundance of programmed death-ligand 1 (PD-L1) expression and identify rational candidates for anti-PD-1/PD-L1 immunotherapies in cervical cancer. Patients and Methods: In 27 patients with FIGO stage IBI-IIA cervical cancer, paraffin-embedded tumors were immunohistochemically stained with PD-L1 antibody. The correlation of tumoral PDL1 expression with clinicopathological factors and survival outcomes were evaluated. Results: Overall, PD-LI expression was primarily detected in 12 (44.4\%) patients. All tumors with PD-L1 expression were squamous cell carcinomas $(S q C C)$. In subgroup analysis of $S q C C$, higher $P D-L 1$ expression was associated with low preoperative serum SqCC antigen level $(p=0.030)$ and no parametrial invasion $(p=0.048)$. The 5-year progression-free survival ( $83.3 \%$ vs. $50.0 \%, p=0.136)$ and overall survival rates (90.9\% vs. $83.3 \%, p=0.615)$ were superior in patients with $P D-L 1$ expression that in those without PD-L1 expression; however, neither was significant. Conclusion: Patients with $S q C C$ and favorable clinicopathological factors could be candidates for anti-PD-1/PD-L1 immunotherapy in cervical cancer.
\end{abstract}

Infection with an oncogenic human papillomavirus (HPV) is associated with $5 \%$ of all human cancers, including squamous cell carcinoma (SqCC) of the vulva, vagina, penis, larynx and head/neck; predominantly cervical cancer and other anogenital cancers (1). HPV E7 protein blocks

Correspondence to: Jae Hong No, Department of Obstetrics and Gynecology, Seoul National University Bundang Hospital, 82 Gumi-ro 173 Beon-gil, Bundang-gu, Seongnam-si, Gyeonggi-do 13620, Republic of Korea. Tel: +82 317877258, Fax: +82 317874054,e-mail: jhno@snu.ac.kr

Key Words: Programmed death-ligand 1, cervical cancer, squamous cell carcinoma, immunohistochemistry. interferon (IFN)- $\alpha$ activity by inhibiting the expression of inducible target genes of IFN signaling pathways that are important for cellular immunity $(2,3)$. In HPV-associated cancers, improved understanding of the role of the immunity has led to the identification of novel therapeutic targets in immune checkpoint pathways. Nearly all immune checkpoints are initiated by ligand-receptor interactions; therefore, they can be blocked by antibodies of their ligands or receptors.

Programed cell death-1 (PD-1) is a key immune checkpoint molecule that has two principal ligands known as programed death-ligand 1 (PD-L1) and PD-L2. PD-1/PD-L1 interaction inhibits signaling of the T-cell receptor, downregulates the secretion of immuno-stimulatory cytokines, and increases T-cell production of the immunosuppressive cytokine. Thus, PD-L1 may have a vital role in the process by which tumor cells escape immunity through PD-1/PD-L1 interaction. Over the past decade, several immune checkpoint inhibitors targeting the PD-1/PD-L1 signaling pathway have exhibited a reliable therapeutic response in clinical trials in several malignancies (4-13). With these promising results, identifying factors predicting clinical response against antiPD-1/PD-L1 therapies could guide therapeutic optimization. Therefore, attempts to reveal the association of tumor microenvironmental features with PD-1/PD-L1 expression in tumor cells or infiltrating immune cells have been continued.

Taube et al. suggested that tumoral PD-L1 expression correlated with an objective response (complete or partial regression [decrease in the sum of diameters of target lesions $\geq 30 \%$ ] by RECIST 1.0 ) to anti-PD- 1 therapy, as indicated by an analysis of the specimens obtained closest to therapy or the highest scoring sample among multiple biopsies from individual patients with several solid malignancies $(14,15)$. Intratumoral PD-L1 expression has already been detected in various malignancies of the head and neck, lung, kidney, breast, and ovary (16). However, in cervical cancer, until now, there has been a relative lack of experimental evidence for the abundance of tumoral PD-L1 expression and its 
clinical relevance. Recently, some authors have only begun to focus on PD-L1 expression in a cohort of primary tumor samples of cervical cancer using immunohistochemistry staining (17-19). However, as there is disagreement in the percentage of cervical cancer tumor samples that express PD-L1, its clinical relevance in identifying rational candidates for therapies targeting PD-L1 has not been demonstrated. There also remains a group of patients where treatment options remain limited.

In this retrospective observational study, we investigated the abundance of PD-L1 expression in cervical cancer tumors and its clinical relevance for identifying rational candidates for immunotherapies targeting PD-1/PD-L1.

\section{Materials and Methods}

Study group. Formalin-fixed, paraffin-embedded tissues were collected from a total of 27 patients with cervical cancer. All recruited patients were diagnosed with the International Federation of Gynecology and Obstetrics (FIGO) stage IB to IIA cervical cancer and underwent surgery as primary treatment in a single institution between August 2011 and October 2012. Patients with a prior malignancy that occurred less than 5 years from enrollment were excluded. Patient samples were handled and used in accordance with the medical ethical guidelines described in the Code of Conduct for Proper Secondary Use of Human Tissue of the Dutch Federation of Biomedical Scientific Societies. All patients provided written informed consent to participate in this study, whose protocol was approved by the institutional review board (B-1707-406-304).

Before surgery, the preoperative serum SqCC antigen level was evaluated using a radioimmunoassay. A level $\geq 2.0 \mathrm{ng} / \mathrm{ml}$ was considered abnormal. All enrolled patients underwent surgery that included radical hysterectomy and pelvic lymph node dissection. Bilateral salpingo-oophorectomy and para-aortic lymph node dissection were performed according to the surgeon's discretion. Surgical specimens were reviewed by a pathologist specializing in a gynecologic pathology who was blinded to the patients' outcomes. We obtained the final pathologic results, which included histologic type, tumor size, depth of stromal invasion, lymphovascular space invasion (LVSI), parametrial invasion, involved lymph nodes, and surgical margin involvement. Sedlis criteria were satisfied in the following cases: LVSI positive, deep one-third stromal invasion, any size; LVSI positive, middle one-third stromal invasion, $\geq 2.0 \mathrm{~cm}$; LVSI positive, superficial one-third stromal invasion, $\geq 5.0 \mathrm{~cm}$; LVSI negative, middle or deep one-third, $\geq 4.0 \mathrm{~cm}$. In accordance with the clinical policies of each surgeon, adjuvant therapy was administered after surgery to patients whose final pathologic results indicated intermediate or high-risk.

Immunohistochemistry. Formalin-fixed and paraffin-embedded tissues were sectioned at a thickness of $4 \mu \mathrm{m}$ and stained using an automated immunostainer (Ventana Medical Systems, Tucson, AZ), according to the manufacturer's protocol. Briefly, the slides were dried at $60^{\circ} \mathrm{C}$ for 1 hand deparaffinized using EZ Prep (Ventana Medical Systems) at $75^{\circ} \mathrm{C}$ for $4 \mathrm{~min}$. The cells were conditioned (heat pretreatment) using a $\mathrm{CC} 1$ solution containing Tris/borate/ ethylenediaminetetraacetic acid at $100^{\circ} \mathrm{C}$ for $20 \mathrm{~min}$. The antibody for PD-L1 (rabbit monoclonal, clone 28-8 [ab205921], Abcam, Cambridge, United Kingdom) was diluted to
1:500, applied to sections, and incubated at $37^{\circ} \mathrm{C}$ for $32 \mathrm{~min}$. Signals were detected using an ultra-view detection kit (Ventana Medical Systems) with labeled streptavidin-biotin. The steps used with the kit included treatment with an inhibitor $\left(1 \% \mathrm{H}_{2} \mathrm{O}_{2}, 4 \mathrm{~min}\right)$, biotinylated immunoglobulin ( $8 \mathrm{~min})$, streptavidin horseradish peroxidase $(8 \mathrm{~min})$, diaminobenzidine (chromogen+substrate) ( $8 \mathrm{~min}$ ), and copper (4 min) at $37^{\circ} \mathrm{C}$. Counterstaining was performed with Mayer's hematoxylin (ScyTek, Logan, UT) for $2 \mathrm{~min}$ at room temperature.

Evaluation of PD-L1 expression. PD-L1 expression was defined in tumor cells if membranous and/or cytoplasmic staining was present with $>1 \%$. PD-L1 immunostaining was classified into four groups according to intensity and extent as follows: grade 0 , negative in tumor cells; grade 1, focal weak PD-L1 expression; grade 2, focal moderate PD-L1 expression; grade 3, diffuse PD-L1 expression (Figure 1).

Statistical analysis. Correlation between PD-L1 expression and various clinicopathologic factors were analyzed by Fisher's exact test or linear association, as appropriate. Progression-free survival (PFS) and overall survival (OS) were assessed by the Kaplan-Meier curves, while log rank test was used for comparison. A two sided $p$-value of $<0.05$ was considered statistically significant. SPSS version 22.0 (IBM Inc., Armonk, NY, USA) was used for statistical analyses.

\section{Results}

Association between PD-L1 expression and clinicopathological factors. Baseline characteristics of the 27 patients with cervical cancer are summarized in Table I. The median age was 46 (range $=34-71$ ) years, and the median follow-up period was 59 (range=23-66) months. Sixteen (59.3\%) patients were diagnosed with FIGO stage IB1 cervical cancer after surgery of radical hysterectomy and pelvic lymph node dissection. Eighteen (66.7\%) patients had SqCC, and 9 (33.3\%) patients had adenocarcinoma. Although Sedlis criteria were satisfied in $13(48.1 \%)$ patients, $16(59.3 \%)$ patients received adjuvant radiotherapy at their physician's discretion. Five (18.5\%) patients experienced recurrence, and $3(11.1 \%)$ patients had deceased at the time of analysis.

Overall, PD-L1 expression was detected in 12 (44.4\%) patients with cervical cancer (Table II). Notably, all tumors with PD-L1 expression had SqCC histology (SqCC vs. adenocarcinoma, 12/18 [66.7\%] vs. 0/9 [0\%], $p=0.001)$. However, except from histology, none of the evaluated clinicopathological factors were significantly associated with a positive PD-L1 expression. The incidences of recurrence (16.7\% vs. $20.0 \%, p>0.999)$ and death $(8.3 \%$ vs. $13.3 \%$, $p>0.999)$ were also similar between patients with and without PD-L1 expression.

$P D-L 1$ expression pattern in patients with cervical $S q C C$. In a subgroup analysis of SqCC $(n=18)$, positive PD-L1 expression was also not associated with any clinicopathological factors (data not shown). However, high-grade PD-L1 expression was 

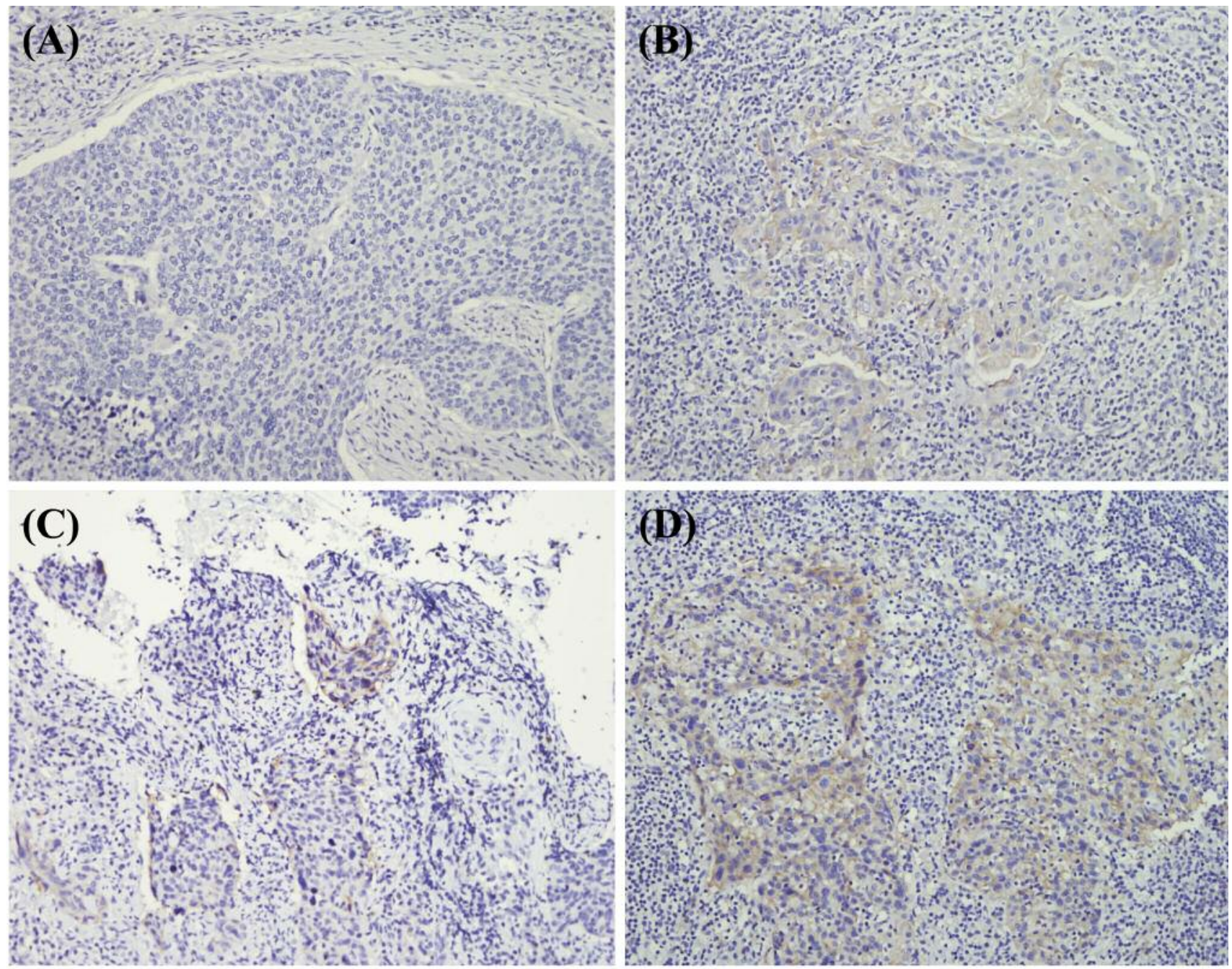

Figure 1. Immunohistochemical staining for PD-L1 expression in tumor cells (A) grade 0, negative control; (B) grade 1, focal weak PD-L1 expression; (C) grade 2, focal moderate PD-L1 expression; (D) grade 3, diffuse PD-L1 expression; original magnification $\times 200$. PD-L1: programmed death-ligand 1 .

detected more frequently in tumors with preoperative serum SqCC antigen $<2.0 \mathrm{ng} / \mathrm{ml}$ than in tumors with $\geq 2.0 \mathrm{ng} / \mathrm{ml}$ $(p=0.030)$ (Table III). High-grade PD-L1 expression was also significantly more in tumors without parametrial invasion than in tumors with parametrial invasion $(p=0.048)$. PD-L1 expression over grade 2 was not detected in tumors with surgical margin involvement; however, it was not statistically significant $(p=0.322)$.

Survival outcomes in patients with vs. without PD-L1 expression. In the entire study population, the 5-year PFS rates were similar between patients with and without PD-L1 expression (83.3\% vs. 80.0\%, $p=0.831$ ) (Figure 2). PD-L1 expression was also not significantly associated with the 5year OS (positive vs. negative, 90.9\% vs. 93.3\%. $p=0.845$ ).
In a subgroup analysis of SqCC, the 5-year PFS rate was revealed to be superior in patients with PD-L1 expression than in those without (83.3\% vs. 50.0\%. $p=0.136)$. However, it was not statistically significant. There was no difference in the 5-year OS rates in patients with $\mathrm{SqCC}$, according to PD-L1 expression (positive vs. negative, $90.9 \%$ vs. $83.3 \%$, $p=0.615$ ).

\section{Discussion}

Tumoral PD-L1 expression has been detected in several solid malignancies with various percentages (24.2-46.1\%) (20-24). The overall rate of PD-L1 expression in cervical cancer tumors in our cohort (44.4\%) was similar to that observed in other malignancies. In our study, PD-L1 expression was 
Table I. Patient characteristics $(n=27)$.

\begin{tabular}{|c|c|}
\hline Parameter & Value \\
\hline Age & $46(34-71)$ \\
\hline \multicolumn{2}{|l|}{ FIGO stage } \\
\hline IB1 & $16(59.3)$ \\
\hline IB2 & $7(25.9)$ \\
\hline IIA & $4(14.8)$ \\
\hline \multicolumn{2}{|l|}{ Histology } \\
\hline $\mathrm{SqCC}$ & $18(66.7)$ \\
\hline Adenocarcinoma & $9(33.3)$ \\
\hline \multicolumn{2}{|c|}{ Preoperative serum $\mathrm{SqCC}$ antigen, $\mathrm{ng} / \mathrm{ml}^{\dagger}$} \\
\hline$<2.0$ & $12(70.6)$ \\
\hline$\geq 2.0$ & $5(29.4)$ \\
\hline \multicolumn{2}{|l|}{ Tumor size, $\mathrm{cm}$} \\
\hline$<2.0$ & $7(25.9)$ \\
\hline$\geq 2.0$ & $20(74.1)$ \\
\hline \multicolumn{2}{|l|}{ Depth of stromal invasion } \\
\hline$<1 / 3$ & $7(25.9)$ \\
\hline $1 / 3 \leq,<2 / 3$ & $9(33.3)$ \\
\hline$\geq 2 / 3$ & $11(40.7)$ \\
\hline \multicolumn{2}{|c|}{ Lymphovascular space invasion } \\
\hline No & $14(51.9)$ \\
\hline Yes & $13(48.1)$ \\
\hline \multicolumn{2}{|l|}{ Parametrial invasion } \\
\hline No & $23(85.2)$ \\
\hline Yes & $4(14.8)$ \\
\hline \multicolumn{2}{|l|}{ Lymph node metastasis } \\
\hline No & $21(77.8)$ \\
\hline Yes & $6(22.2)$ \\
\hline \multicolumn{2}{|c|}{ Surgical margin involvement } \\
\hline No & $25(92.6)$ \\
\hline Yes & $2(7.4)$ \\
\hline \multicolumn{2}{|l|}{ Satisfying Sedlis criteria ${ }^{\ddagger}$} \\
\hline No & $14(51.9)$ \\
\hline Yes & $13(48.1)$ \\
\hline \multicolumn{2}{|l|}{ Adjuvant radiotherapy } \\
\hline No & $11(40.7)$ \\
\hline Yes & $16(59.3)$ \\
\hline Follow-up period, month & $59(23-66)$ \\
\hline \multicolumn{2}{|l|}{ Recurrence } \\
\hline No & $22(81.5)$ \\
\hline Yes & $5(18.5)$ \\
\hline \multicolumn{2}{|l|}{ Death } \\
\hline No & $24(88.9)$ \\
\hline Yes & $3(11.1)$ \\
\hline
\end{tabular}

FIGO: The International Federation of Gynecology and Obstetrics: SqCC: squamous cell carcinoma. †only in SqCC histology. $¥$ Lymphovascular space invasion (LVSI) positive, deep 1/3 stromal invasion, any size; LVSI positive, middle $1 / 3$ stromal invasion, $\geq 2.0 \mathrm{~cm}$; LVSI positive, superficial $1 / 3$ stromal invasion, $\geq 5.0 \mathrm{~cm}$; LVSI negative, middle or deep $1 / 3, \geq 4.0 \mathrm{~cm}$.

detected only in tumors that were confirmed to exhibit SqCC histology, and the frequency of PD-L1 expression was separately estimated to be $66.7 \%$ according to $\mathrm{SqCC}$ histology. Heeren et al. reported that PD-L1 expression in cervical cancer was significantly more observed in SqCC
Table II. Clinicopathological characteristics in patients with vs. without PD-L1 expression.

\begin{tabular}{|c|c|c|c|}
\hline \multirow[t]{2}{*}{ Parameter } & \multicolumn{2}{|c|}{ PD-L1 expression } & \multirow[t]{2}{*}{$p$-Value } \\
\hline & $\begin{array}{l}\text { Negative } \\
(n=15)\end{array}$ & $\begin{array}{c}\text { Positive } \\
(\mathrm{n}=12)\end{array}$ & \\
\hline Age & $45.3 \pm 7.7$ & $51.5 \pm 11.1$ & 0.100 \\
\hline FIGO stage & & & 0.930 \\
\hline IB1 & $9(60.0)$ & $7(58.3)$ & \\
\hline IB2-IIA & $6(40.0)$ & $5(41.7)$ & \\
\hline Histology & & & 0.001 \\
\hline $\mathrm{SqCC}$ & $6(40.0)$ & $12(100)$ & \\
\hline Adenocarcinoma & $9(60.0)$ & 0 & \\
\hline \multicolumn{4}{|l|}{ Preoperative serum } \\
\hline SqCC antigen, ng/ml & & & 0.117 \\
\hline$<2.0$ & $2(40.0)$ & $10(83.3)$ & \\
\hline$\geq 2.0$ & $3(60.0)$ & $2(16.7)$ & \\
\hline Tumor size, $\mathrm{cm}$ & & & $>0.999$ \\
\hline$<2.0$ & $4(26.7)$ & $3(25.0)$ & \\
\hline$\geq 2.0$ & $11(73.3)$ & $9(75.0)$ & \\
\hline Depth of stromal invasion & & & 0.293 \\
\hline$<1 / 3$ & $6(40.0)$ & $1(8.3)$ & \\
\hline $1 / 3 \leq,<2 / 3$ & $3(20.0)$ & $6(50.0)$ & \\
\hline$\geq 2 / 3$ & $6(40.0)$ & $5(41.7)$ & \\
\hline Lymphovascular space invasion & & & 0.547 \\
\hline No & $7(46.7)$ & $7(58.3)$ & \\
\hline Yes & $8(53.3)$ & $5(41.7)$ & \\
\hline Parametrial invasion & & & 0.605 \\
\hline No & $12(80.0)$ & $11(91.7)$ & \\
\hline Yes & $3(20.0)$ & $1(8.3)$ & \\
\hline Lymph node metastasis & & & 0.182 \\
\hline No & $10(66.7)$ & $11(91.7)$ & \\
\hline Yes & $5(33.3)$ & $1(8.3)$ & \\
\hline Surgical margin involvement & & & $>0.999$ \\
\hline No & $14(93.3)$ & $11(91.7)$ & \\
\hline Yes & $1(6.7)$ & $1(8.3)$ & \\
\hline Satisfying Sedlis criteria $\ddagger$ & & & 0.863 \\
\hline No & $8(53.3)$ & $6(50.0)$ & \\
\hline Yes & $7(46.7)$ & $6(50.0)$ & \\
\hline Adjuvant radiotherapy & & & 0.930 \\
\hline No & $6(40.0)$ & $5(41.7)$ & \\
\hline Yes & $9(60.0)$ & $7(58.3)$ & \\
\hline Recurrence & & & $>0.999$ \\
\hline No & $12(80.0)$ & $10(83.3)$ & \\
\hline Yes & $3(20.0)$ & $2(16.7)$ & \\
\hline Death & & & $>0.999$ \\
\hline No & $13(86.7)$ & $11(91.7)$ & \\
\hline Yes & $2(13.3)$ & $1(8.3)$ & \\
\hline
\end{tabular}

PD-L1: Programmed death-ligand 1; SqCC: squamous cell carcinoma; FIGO: The International Federation of Gynecology and Obstetrics.

than in adenocarcinoma (54\% vs. $14 \%, p<0.001)(17)$. Mezache et al. also showed notable PD-L1 expression in $51 \%$ of cervical SqCC cases (19). Adding to these significant rates of tumoral PD-L1 expression, our findings could suggest that the PD-1/PD-L1 pathway might be a promising 
Table III. Clinicopathological characteristics according to the grade of PD-L1 expression in patients with squamous cell carcinoma ( $n=18$ ).

\begin{tabular}{|c|c|c|c|c|c|}
\hline \multirow[t]{2}{*}{ Parameter } & \multicolumn{4}{|c|}{ PD-L1 expression grade } & \multirow[t]{2}{*}{$p$-Value } \\
\hline & $0(n=6)$ & $1(\mathrm{n}=5)$ & $2(n=3)$ & $3(n=4)$ & \\
\hline Age & & & & & 0.371 \\
\hline$<50$ & $4(66.7)$ & $1(20.0)$ & $2(66.7)$ & $1(25.0)$ & \\
\hline$\geq 50$ & $2(33.3)$ & $4(80.0)$ & $1(33.3)$ & $3(75.0)$ & \\
\hline Preoperative serum $\mathrm{SqCC}$ antigen, $\mathrm{ng} / \mathrm{ml}$ & & & & & 0.030 \\
\hline$<2.0$ & $2(40.0)$ & $3(60.0)$ & $3(100)$ & $4(100)$ & \\
\hline$\geq 2.0$ & $3(60.0)$ & $2(40.0)$ & 0 & 0 & \\
\hline FIGO stage & & & & & 0.227 \\
\hline IB1 & $4(66.7)$ & $1(20.0)$ & $2(66.7)$ & $4(100)$ & \\
\hline IB2-IIA & $2(33.3)$ & $4(80.0)$ & $1(33.3)$ & 0 & \\
\hline Tumor size, $\mathrm{cm}$ & & & & & 0.785 \\
\hline$<2.0$ & $2(33.3)$ & $1(20.0)$ & 0 & $2(50.0)$ & \\
\hline$\geq 2.0$ & $4(66.7)$ & $4(80.0)$ & $3(100)$ & $2(50.0)$ & \\
\hline Depth of stromal invasion & & & & & 0.929 \\
\hline$<1 / 3$ & $2(33.3)$ & 0 & $1(33.3)$ & 0 & \\
\hline $1 / 3 \leq,<2 / 3$ & 0 & $3(60.0)$ & $1(33.3)$ & $2(50.0)$ & \\
\hline$\geq 2 / 3$ & $4(66.7)$ & $2(40.0)$ & $1(33.3)$ & $2(50.0)$ & \\
\hline Lymphovascular space invasion & & & & & 0.549 \\
\hline No & $2(33.3)$ & $3(60.0)$ & $2(66.7)$ & $2(50.0)$ & \\
\hline Yes & $4(66.7)$ & $2(40.0)$ & $1(33.3)$ & $2(50.0)$ & \\
\hline Parametrial invasion & & & & & 0.048 \\
\hline No & $3(50.0)$ & $4(80.0)$ & $3(100)$ & $4(100)$ & \\
\hline Yes & $3(50.0)$ & $1(20.0)$ & 0 & 0 & \\
\hline Lymph node metastasis & & & & & 0.310 \\
\hline No & $3(50.0)$ & $5(100)$ & $3(100)$ & $3(75.0)$ & \\
\hline Yes & $3(50.0)$ & 0 & 0 & $1(25.0)$ & \\
\hline Surgical margin involvement & & & & & 0.322 \\
\hline No & $5(83.3)$ & $4(80.0)$ & $3(100)$ & $4(100)$ & \\
\hline Yes & $1(16.7)$ & $1(20.0)$ & 0 & 0 & \\
\hline Satisfying Sedlis criteria & & & & & 0.841 \\
\hline No & $3(50.0)$ & $2(40.0)$ & $2(66.7)$ & $2(50.0)$ & \\
\hline Yes & $3(50.0)$ & $3(60.0)$ & $1(33.3)$ & $2(50.0)$ & \\
\hline Adjuvant radiotherapy & & & & & 0.322 \\
\hline No & $1(16.7)$ & $2(40.0)$ & $1(33.3)$ & $2(50.0)$ & \\
\hline Yes & $5(83.3)$ & $3(60.0)$ & $2(66.7)$ & $2(50.0)$ & \\
\hline Recurrence & & & & & 0.535 \\
\hline No & $3(50.0)$ & $5(100)$ & $2(66.7)$ & $3(75.0)$ & \\
\hline Yes & $3(50.0)$ & 0 & $1(33.3)$ & $1(25.0)$ & \\
\hline Death & & & & & 0.724 \\
\hline No & $5(83.3)$ & $5(100)$ & $2(66.7)$ & $4(100)$ & \\
\hline Yes & $1(16.7)$ & 0 & $1(33.3)$ & 0 & \\
\hline
\end{tabular}

PD-L1: Programmed death-ligand 1; SqCC: squamous cell carcinoma; FIGO: The International Federation of Gynecology and Obstetrics.

immunotherapy target in patients with cervical cancer who exhibited SqCC histology.

PD-L1 was highly expressed in tumors with favorable clinicopathologic factors (preoperative serum SqCC antigen $<2.0 \mathrm{ng} / \mathrm{ml} \quad[p=0.030]$ and no parametrial invasion $[p=0.048])$ in tumors with SqCC histology. As indicated by these results, it is important to predict patients who will respond to anti-PD-1/PD-L1 according to the tumor microenvironment types based on the presence or absence of
PD-L1 expression. Teng et al. proposed the classification of tumors into four groups based on their PD-L1 expression status and presence or absence of tumor-infiltrating lymphocytes (TILs) (25). These researchers suggested that tumors with TIL showing positivity of PD-L1 are most likely to benefit from immunotherapies of anti-PD-1/PD-L1 blockade, as these tumors have intratumoral $\mathrm{T}$ cells that are turned-off by interaction with PD-L1. Ngiow et al. also found that the presence of $\mathrm{T}$ cells with low tumoral PD-1 

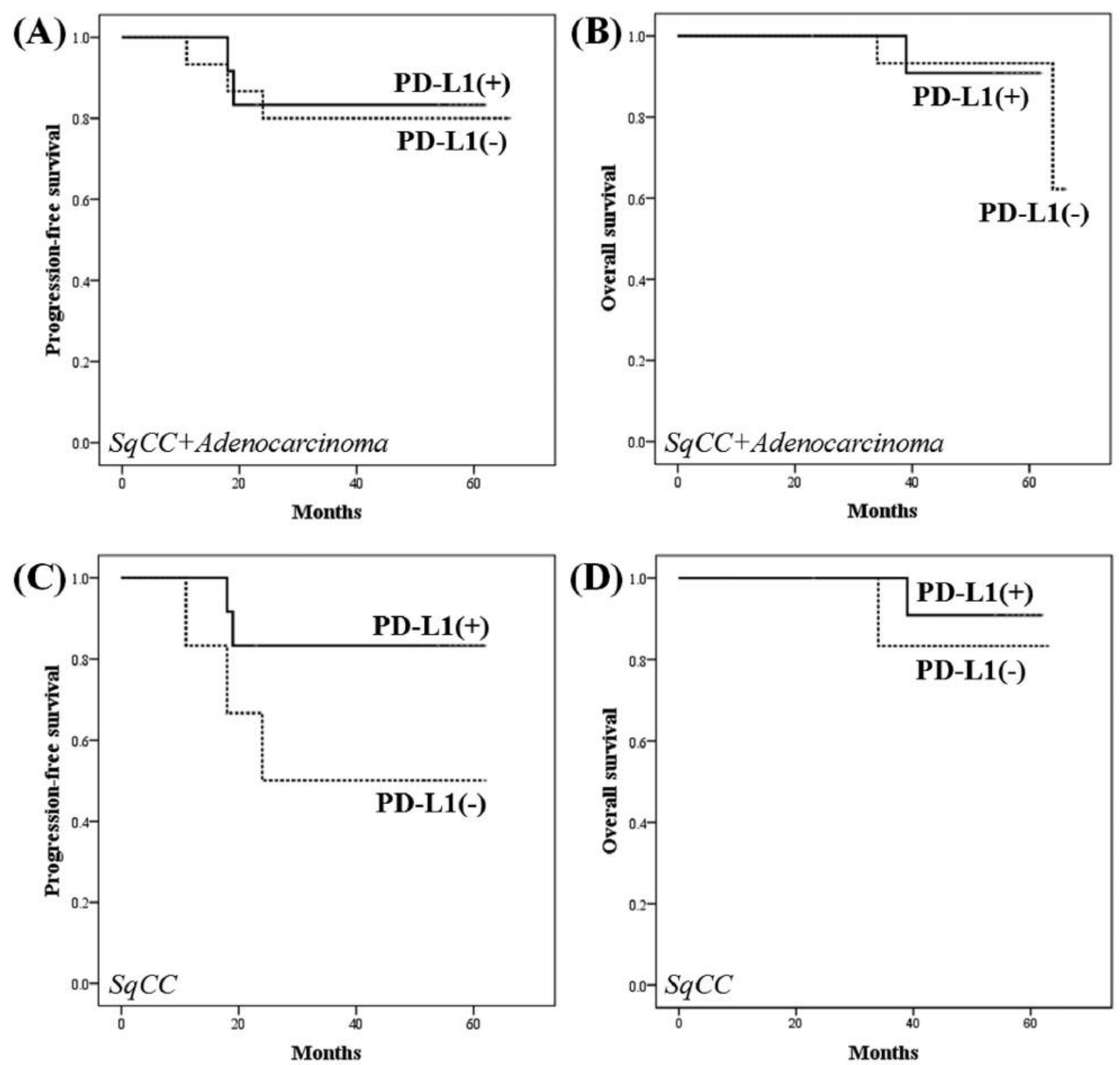

Figure 2. Survival outcomes according to the detection of PD-L1 expression (solid line: positive vs. dotted line: negative); (A) 5-year progressionfree survival of the entire study population ( $83.3 \% \mathrm{vs.} 80.0 \%, p=0.831)$; (B) 5-year overall survival of the entire study population (90.9\% vs. $93.3 \%$, $p=0.845)$; (C) 5-year progression-free survival of patients with SqCC (83.3\% vs. 50.0\%, $p=0.136) ;(D)$-year overall survival of patients with SqCC (90.9\% vs. $83.3 \%, p=0.615)$. PD-L1: programmed death-ligand 1; SqCC: squamous cell carcinoma.

expression positively predicted responses to anti-PD-1 antibody (26). They suggested that low PD-1 T cells produced higher levels of IFN- $\gamma$ and TNF compared to high PD-1 T cells, which might induce PD-L1 expression in the tumor microenvironment. Considering the correlation of tumoral PD-L1 expression with the response to anti-PD1/PD-L1 therapy, patients with tumoral low PD-1/high PDL1 expression might be good candidates for clinical trials involving PD-1/PD-L1 blockade $(14,16)$. Currently, clinical phase I/II trials examining the effects of AGEN2034 (NCT03104699) and nivolumab (NCT02488759, NCT02257528) for only advanced or recurrent cervical cancer are ongoing. These study results have not yet been reported; however, recently, Martínez et al. presented a heavily pretreated patient with recurrent advanced cervical SqCC who had exhausted all available treatment options and showed a striking response to the immune checkpoint inhibitor pembrolizumab (27). 
PFS was favorable in patients with cervical SqCC with PD-L1 expression than in those without PD-L1 expression; however, this observation was not statistically significant (83.3\% vs. 50.0\%, $p=0.136$ ). Regarding the limitations of our study, the small sample size might lower the statistical power of our analysis. Furthermore, discrepancies exist regarding the prognostic role of PD-L1 expression in each malignancy. Some analysis has suggested that patients with high tumoral PD-L1 expression had significantly poorer survival outcomes (22, 28-30), while some did not $(24,31,32)$. Amid the growing controversy, Karim et al. found that PD-L1 may improve OS in a small subgroup of cervical cancer patients with tumors that are relatively heavily infiltrated by regulatory $\mathrm{T}$ cells with low $\mathrm{CD}^{+} /$regulatory $\mathrm{T}$-cell ratio ( $p=0.033$ ) (33). Heeren et al. showed that patients who had cervical SqCC with diffuse PD-L1 expression or no PD-L1 expression exhibited worse PFS ( $p=0.022$ and $p=0.029$, respectively) in comparison to patients with marginal PD-L1 expression in tumors (17). The prognostic role of PD-L1 expression in cervical cancer will be determined after resolving the problems associated with a small sample size, short-term follow-up, history of therapy, intratumoral heterogeneity, or the antibody used to detect PD-L1.

In conclusion, we showed that PD-L1 was more frequently expressed by SqCC than by adenocarcinoma. Although the efficacy of immunotherapies for cervical cancer has not been elucidated, our data suggest that targeting the PD-1/PD-L1 pathway could be a therapeutic target for cervical SqCC. Further large trials for cervical cancer cohorts consisting of rational candidates are warranted so that immunotherapies targeting PD-1/PD-L1 can soon be translated from the bench to the clinic.

\section{Conflicts of Interest}

The Authors declare no conflicts of interest.

\section{Acknowledgements}

This work was supported by a grant (No. 02-2013-018) from the Seoul National University Bundang Hospital Research Fund.

\section{References}

1 Stanley M: HPV-immune response to infection and vaccination. Infect Agent Cancer 5: 19, 2010.

2 Patel S and Chiplunkar S: Host immune responses to cervical cancer. Curr Opin Obstet Gynecol 21: 54-59, 2009.

3 Economopoulou P, Perisanidis C, Giotakis EI and Psyrri A: The emerging role of immunotherapy in head and neck squamous cell carcinoma (HNSCC): anti-tumor immunity and clinical applications. Ann Transl Med 4: 173, 2016.

4 Ott PA, Bang YJ, Berton-Rigaud D, Elez E, Pishvaian MJ, Rugo HS, Puzanov I, Mehnert JM, Aung KL, Lopez J, Carrigan M, Saraf S, Chen M and Soria JC: Safety and antitumor activity of
Pembrolizumab in advanced Programmed Death Ligand 1positive endometrial cancer: Results from the KEYNOTE-028 Study. J Clin Oncol, 2017. doi: 10.1200/JCO.2017.72.5952. [Epub ahead of print]

5 Ning YM, Suzman D, Maher VE, Zhang L, Tang S, Ricks T, Palmby T, Fu W, Liu Q, Goldberg KB, Kim G and Pazdur R: FDA Approval Summary: Atezolizumab for the treatment of patients with progressive advanced urothelial carcinoma after platinumcontaining chemotherapy. Oncologist 22: 743-749, 2017.

6 Bauml J, Seiwert TY, Pfister DG, Worden F, Liu SV, Gilbert J, Saba NF, Weiss J, Wirth L, Sukari A, Kang H, Gibson MK, Massarelli E, Powell S, Meister A, Shu X, Cheng JD and Haddad R: Pembrolizumab for platinum- and cetuximabrefractory head and neck cancer: Results from a single-Arm, Phase II Study. J Clin Oncol 35: 1542-1549, 2017.

7 Daud AI, Wolchok JD, Robert C, Hwu WJ, Weber JS, Ribas A, Hodi FS, Joshua AM, Kefford R, Hersey P, Joseph R, Gangadhar TC, Dronca R, Patnaik A, Zarour H, Roach C, Toland G, Lunceford JK, Li XN, Emancipator K, Dolled-Filhart M, Kang SP, Ebbinghaus S and Hamid O: Programmed death-ligand 1 expression and response to the anti-programmed death 1 antibody pembrolizumab in melanoma. J Clin Oncol 34: 4102-4109, 2016.

8 Gulley JL, Rajan A, Spigel DR, Iannotti N, Chandler J, Wong DJL, Leach J, Edenfield WJ, Wang D, Grote HJ, Heydebreck AV, Chin K, Cuillerot JM and Kelly K: Avelumab for patients with previously treated metastatic or recurrent non-small-cell lung cancer (JAVELIN Solid Tumor): dose-expansion cohort of a multicentre, open-label, phase $1 \mathrm{~b}$ trial. Lancet Oncol 18: 599610, 2017.

9 Massard C, Gordon MS, Sharma S, Rafii S, Wainberg ZA, Luke J, Curiel TJ, Colon-Otero G, Hamid O, Sanborn RE, O'Donnell PH, Drakaki A, Tan W, Kurland JF, Rebelatto MC, Jin X, BlakeHaskins JA, Gupta A and Segal NH: Safety and efficacy of durvalumab (medi4736), an anti-programmed cell death ligand1 immune checkpoint inhibitor, in patients with advanced urothelial bladder cancer. J Clin Oncol 34: 3119-3125, 2016.

10 Bosch-Barrera J, Holguin F, Baldó X, Rubio M, Porta R, Fuentes R, Teixidó C, Ramirez JL, Ferran N, Sebastián F and Rosell R: Neoadjuvant chemoradiotherapy treatment for a classic biphasic pulmonary blastoma with high PD-L1 expression. Anticancer Res 35: 4871-4875, 2015.

11 Shindo Y, Yoshimura K, Kuramasu A, Watanabe Y, Ito H, Kondo T, Oga A, Ito H, Yoshino S, Hazama S, Tamada K, Yagita H and Oka M: Combination immunotherapy with 4-1BB activation and PD-1 blockade enhances antitumor efficacy in a mouse model of subcutaneous tumor. Anticancer Res 35: 129-136, 2015.

12 Koido S, Kan S, Yoshida K, Yoshizaki S, Takakura K, Namiki Y, Tsukinaga S, Odahara S, Kajihara M, Okamoto M, Ito M, Yusa S, Gong J, Sugiyama H, Ohkusa T, Homma S and Tajiri H: Immunogenic modulation of cholangiocarcinoma cells by chemoimmunotherapy. Anticancer Res 34: 6353-6362, 2014.

13 Shosu K, Sakurai M, Inoue K, Nakagawa T, Sakai H, Morimoto M, Okuda M, Noguchi S and Mizuno T: Programmed Cell Death Ligand 1 Expression in Canine Cancer. In Vivo 30: 195-204, 2016.

14 Taube JM, Klein A, Brahmer JR, Xu H, Pan X, Kim JH, Chen L, Pardoll DM, Topalian SL and Anders RA: Association of PD1 , PD-1 ligands, and other features of the tumor immune microenvironment with response to anti-PD-1 therapy. Clin Cancer Res 20: 5064-5074, 2014. 
15 Therasse P, Arbuck SG, Eisenhauer EA, Wanders J, Kaplan RS, Rubinstein L, Verweij J, van Glabbeke M, van Oosterom AT, Christian MC and Gwyther SG: New guidelines to evaluate the response to treatment in solid tumors. European Organization for Research and Treatment of Cancer, National Cancer Institute of the United States, National Cancer Institute of Canada. J Natl Cancer Inst 92: 205-216, 2000.

16 Guan J, Lim KS, Mekhail T and Chang CC: Programmed Death Ligand-1 (PD-L1) expression in the programmed death receptor1 (PD-1)/PD-L1 Blockade: A Key Player Against Various Cancers. Arch Pathol Lab Med 141: 851-861, 2017.

17 Heeren AM, Punt S, Bleeker MC, Gaarenstroom KN, van der Velden J, Kenter GG, de Gruijl TD and Jordanova ES: Prognostic effect of different PD-L1 expression patterns in squamous cell carcinoma and adenocarcinoma of the cervix. Mod Pathol 29: 753-763, 2016.

18 Enwere EK, Kornaga EN, Dean M, Koulis TA, Phan T, Kalantarian M, Köbel M, Ghatage P, Magliocco AM, LeesMiller SP and Doll CM: Expression of PD-L1 and presence of CD8-positive $\mathrm{T}$ cells in pre-treatment specimens of locally advanced cervical cancer. Mod Pathol 30: 577-586, 2017.

19 Mezache L, Paniccia B, Nyinawabera A and Nuovo GJ: Enhanced expression of PD L1 in cervical intraepithelial neoplasia and cervical cancers. Mod Pathol 28: 1594-1602, 2015.

20 Zhou C, Tang J, Sun H, Zheng X, Li Z, Sun T, Li J, Wang S, Zhou X, Sun H, Cheng Z, Zhang $\mathrm{H}$ and Ma H: PD-L1 expression as poor prognostic factor in patients with nonsquamous non-small cell lung cancer. Oncotarget, 2017. doi: 10.18632/oncotarget.17022. [Epub ahead of print]

21 Kim R, Keam B, Kwon D, Ock CY, Kim M, Kim TM, Kim HJ, Jeon YK, Park IK, Kang CH, Kim DW, Kim YT and Heo DS: Programmed death ligand-1 expression and its prognostic role in esophageal squamous cell carcinoma. World J Gastroenterol 22: 8389-8397, 2016.

22 Li Z, Dong P, Ren M, Song Y, Qian X, Yang Y, Li S, Zhang X and Liu F: PD-L1 expression is associated with tumor FOXP3(+) regulatory T-Cell infiltration of breast cancer and poor prognosis of patient. J Cancer 7: 784-793, 2016.

23 Erlmeier F, Weichert W, Schrader AJ, Autenrieth M, Hartmann A, Steffens S and Ivanyi P: Prognostic impact of PD-1 and its ligands in renal cell carcinoma. Med Oncol 34: 99, 2017.

24 Webb JR, Milne K, Kroeger DR and Nelson BH: PD-L1 expression is associated with tumor-infiltrating $\mathrm{T}$ cells and favorable prognosis in high-grade serous ovarian cancer. Gynecol Oncol 141: 293-302, 2016.
25 Teng MW, Ngiow SF, Ribas A and Smyth MJ: Classifying cancers based on t-cell infiltration and PD-L1. Cancer Res 75: 2139-2145, 2015.

26 Ngiow SF, Young A, Jacquelot N, Yamazaki T, Enot D, Zitvogel L and Smyth MJ: A threshold level of intratumor CD8+ T-cell PD1 expression dictates therapeutic response to anti-PD1. Cancer Res 75: 3800-3811, 2015.

27 Martínez P and Del-Campo JM: Pembrolizumab in recurrent advanced cervical squamous carcinoma. Immunotherapy 9: 467470, 2017.

28 Hamanishi J, Mandai M, Iwasaki M, Okazaki T, Tanaka Y, Yamaguchi K, Higuchi T, Yagi H, Takakura K, Minato N, Honjo $\mathrm{T}$ and Fujii S: Programmed cell death 1 ligand 1 and tumorinfiltrating CD8 $+\mathrm{T}$ lymphocytes are prognostic factors of human ovarian cancer. Proc Natl Acad Sci USA 104: 3360-3365, 2007.

29 Muenst S, Schaerli A, Gao F, Däster S, Trella E, Droeser RA, Muraro MG, Zajac P, Zanetti R, Gillanders WE, Weber WP and Soysal SD: Expression of programmed death ligand 1 (PD-L1) is associated with poor prognosis in human breast cancer. Breast Cancer Res Treat 146: 15-24, 2014.

30 Thompson RH, Kuntz SM, Leibovich BC, Dong H, Lohse CM, Webster WS, Sengupta S, Frank I, Parker AS, Zincke H, Blute ML, Sebo TJ, Cheville JC and Kwon ED: Tumor B7-H1 is associated with poor prognosis in renal cell carcinoma patients with long-term follow-up. Cancer Res 66: 3381-3385, 2006.

31 Kogashiwa Y, Yasuda M, Sakurai H, Nakahira M, Sano Y, Gonda K, Ikeda T, Inoue H, Kuba K, Oba S, Ishikawa J, Enoki Y, Matsumura S, Minami K, Ebihara Y and Sugasawa M: PDL1 expression confers better prognosis in locally advanced oral squamous cell carcinoma. Anticancer Res 37: 1417-1424, 2017.

32 Yang CY, Lin MW, Chang YL, Wu CT and Yang PC: Programmed cell death-ligand 1 expression is associated with a favourable immune microenvironment and better overall survival in stage I pulmonary squamous cell carcinoma. Eur J Cancer 57: 91-103, 2016.

33 Karim R, Jordanova ES, Piersma SJ, Kenter GG, Chen L, Boer JM, Melief CJ and van der Burg SH: Tumor-expressed B7-H1 and B7-DC in relation to PD-1+ T-cell infiltration and survival of patients with cervical carcinoma. Clin Cancer Res 15: 63416347, 2009.

Received June 27, 2017

Revised July 5, 2017

Accepted July 6, 2017 